\title{
Efficient adsorption of Malachite Green from water by activated carbon of Date trunk fiber
}

\author{
Muhammad Haroon a *, Rooh Ullah a,b*, Sahid Mehmood c, Saif Ullah ${ }^{\text {d }}$, Nasir Khan ${ }^{\mathrm{e}}$, Fazal Haq ${ }^{\mathrm{f}}$, \\ Naeemullah ${ }^{\mathrm{a}}$, Zafar Ali ${ }^{\mathrm{a}}$, Hammal Majeed ${ }^{\mathrm{a}}$ \\ ${ }^{\text {a }}$ Department of chemistry, University of Turbat (Kech), Balochistan, Pakistan \\ ${ }^{\mathrm{b}}$ Department of Natural and Basic Sciences, University of Turbat, Balochistan, Pakistan \\ ${ }^{\mathrm{c}}$ State Key Laboratory of Chemical Engineering, College of Chemical and Biological Engineering, \\ Zhejiang University, Hangzhou 310027, P.R. China \\ ${ }^{\mathrm{d}}$ Department of Chemistry, Anhui University, Hefei, 230601, People's Republic of China \\ ${ }^{\mathrm{e}}$ School of Petroleum Engineering, China University of Petroleum (East China), Qingdao 266555, China \\ ${ }^{\mathrm{f}}$ Institute of Chemical Sciences, Gomal University, Dera Ismail Khan \\ "Corresponding author's email: roohullah@uot.edu.pk; : burmy_chem@yahoo.com
}

\begin{abstract}
Dyes, which are used in various industries like food, cosmetics, pharmaceutical, textile etc., for various purposes cause diseas es like causes cancer, kidney failure, dysfunction of brain, infertility etc. In this research paper low cost adsorbent (activated carbon) w as prepared from date palm trunk fiber by chemical activation using $\mathrm{H}_{3} \mathrm{PO}_{4}$ as activating agent. The synthesized activated carbon was characterized with FTIR spectroscopy. The FTIR result confirms the introduction of various functionalities like alcohol, esters, carbox ylic acid, benzyl and alkyl functionalities into activated carbon. Crystallinity was checked with XRD pattern, which shows that the acti vated carbon has amorphous nature which is very suitable for adsorption. Finally it was utilized for the adsorption of Malachite Green , a model cationic dye, from water. The various parameters studied include adsorbent amount, $\mathrm{pH}$ and contact time. The optimum con ditions determined were adsorbent dosage $0.5 \mathrm{~g}$, contact time $20 \mathrm{~min}$ and pH5-7. From the result, we conclude that activated carbon of date fiber remains an efficient adsorbent for removal of Cationic dye and may prove the best low cost adsorbent dye-wastewater treat ment.
\end{abstract}

Keywords- Activated carbon; low cost; water; Malachite Green; Adsorption

Date Received: $02-10-2020$

Date Accepted: 26-10-2020

Date Published: 08-06-2021

\section{INTRODUCTION}

W ater is considered very important for life due to its application in every walk of life, but due to the rapid growth of human population and rapid industrialization, water's nature and quality has been polluted in a great extent [1]. Among all of the water polluting agents' like heavy metals, petrochemical wastes and dyes, industrial dyes are ranked at the top for causing acute water pollution and have a huge hand for the generation of contaminated and lethal environment [2]. Dyes are complex natural or synthetic colored organic compounds having interaction with the surface of the substrate molecules to provide color to it because of the presence of the chromophores and auxochromic groups within the molecules of the dyes [3]. The synthetic dyes have a substantial application in the most advanced industries such as textile, paper printing, plastics, leather, food, cosmetics etc. and as a result these are expelling a massive amount of poisonous dyes effluents [4]. According to the latest findings more than 100000 synthetic dyes are identified and it has been reported that globally approximately more than 0.8 million tons of dyes are annually produced [5-8]. These toxic dyes become the cause of serious damage to the human health like kidney failure, damage of liver ,central nervous system ,brain ,reproductive system, hemorrhage, skin related complications etc. Similarly, these toxic dyes and their biodegradable products are reported to be cancer causing, mutagenic and teratogenic for many living species including human [9-10]. Most importantly it has been reported that dyes can become the cause of soil infertility as it cause of the death of many beneficial soil organisms [11].

The release of huge amount of synthetic dyes into the natural water bodies with their destructive nature has put many challenges in front of the environmental experts [12-13]. As a result of this it is a need of time to introduce such an efficient treatment method for the removal of dyes effluents before the releasing of them in natural water bodies. Variety of techniques have been introduced and explored for wastewater treatments including solvent extraction, bio sorption, ion exchange ,coagulation ,electrolysis and adsorption [14] .Out of all these, adsorption has been favored more and extensively utilized for wastewater pollutants treatment as compare to others because of their some disadvantages including slow rate, partial removal ,much energy utilization, production of lethal byproducts and high budget etc. [15]. While on the other, hand adsorption is a rapid and low cost technique with no interaction with the toxic contaminants along with its easy and simple design and operation with the complete extraction of pollutants and has the 
proficiency of removal of variety of pollutants concentration [16].

Variety of adsorbents has been used on commercial scale for wastewater treatment such as charcoal, graphene, activated carbon etc. Among all activated carbon has been favored more. Activated carbon is considered as a universal adsorbent for the removal of organic, inorganic and biological pollutants because of its some special and distinct characteristics such as high surface area, well developed porous structure, non-toxicity, thermal stability, rapid adsorbing capability along with the presence of the various types of extractive functional groups such as alcohol, esters, carboxylic acid, benzyl and alkyl group [17].

Here in this study, activated carbon was prepared from Date palm trunk fiber and was used for the adsorption of Malachite Green from water under different parameters like adsorbent concentration, $\mathrm{pH}$ and contact time. It was found one of the best adsorbents for this purpose.

\section{EXPERIMENTAL SECTION}

\section{A. Materials}

Malachite green, Phosphoric acids, Potassium Hydroxide, Activated Carbon, Sodium Hydroxide, Hydrochloric acid were used. All the chemicals used were of analytical grade.

\section{B. Characterization}

FT-IR spectra were taken by Nicolet 5700 IR spectrometer. For spectral analysis, activated carbon (2mg) was mixed with $\mathrm{KBr}$ (98mg), these were ground together and pallet was prepared. The pallet was then dried to remove any moister content and placed spectrometer to get FTIR spectrum. XRD results were checked with X-ray diffractometer (XPert PRO) equipped with $\mathrm{CuK} \alpha,(\lambda=1.54 \AA)$ at $40 \mathrm{kV}$ and $40 \mathrm{~mA}$. The concentration of dyes adsorbed was calculated from the absorbance results obtained from $3802 \mathrm{UV} / \mathrm{Visible}$ spectrophotometer. As $\boldsymbol{\lambda}_{\max }$ for malachite Green is $617 \mathrm{~nm}$ [18], so absorbance of dye solution was checked at this wavelength.

\section{Collection of sample}

The samples of Date palm trunk fibers were collected from a nearby garden at Jusak turbat kech. The collected samples were washed thoroughly by the tap water 5 times due to which all the dust particles were removed. After that the sample was treated with distilled water thrice so that to make it free from all impurities. Then the sample was put in oven for drying in $24 \mathrm{~h}$ at $110^{\circ} \mathrm{C}$. The dried sample was collected and converted into small pieces by using the scissor and then by the help of the pestle and mortar simple was thoroughly grinded and converted into powdered form.

\section{Preparation of activated carbon}

The powdered form of the collected sample of the Date palm trunk fiber was converted into activated carbon by the application of the Chemical activation method. At first about
$20 \mathrm{~g}$ of the prepared raw material was soaked with 85 weights percent of concentrated phosphoric acid and the mixture was stirred for $3 \mathrm{~h}$. The impregnation ratio of 1:1 was taken. By the impregnation of the raw material with the chemical activating agent slurry gets formed that is put in desiccator. The activation process involved the two stage process including the semi carbonization and carbonization. After $24 \mathrm{~h}$ the slurry was put in a muffle furnace for $30 \mathrm{~min}$ by the provision of temperature of $200^{\circ} \mathrm{C}$, so that to carry on the semi carbonization process. As a result of the semi carbonization the slurry turns out to be black and some sticky and grains like structures get formed. After the completion of the semi carbonization, the second step of the carbonization was performed by putting the slurry into a tubular furnace by heating it to $550{ }^{\circ} \mathrm{C}$ followed by introduction of nitrogen flow of about $100 \mathrm{~cm}^{3}$ in per minute for $45 \mathrm{~min}$. After the completion of the activation the activated carbon is put into desiccators to make it cool and far from the moisture. The synthesized activated carbon was neutralized by constantly washing it with distilled water. The neutralized activated carbon was dried in oven at $110^{\circ} \mathrm{C}$ for one day. The activated carbon with average particle size of $0.14 \mathrm{~mm}$ to $0.24 \mathrm{~mm}$ was collected and placed it in desiccator for further use in adsorption process [19].

\section{E. Preparation of stock solutions of Malachite green}

The Malachite green that looks green in color and in aqueous medium have a bluish green appearance remains a cationic basic based dye having the $\lambda$ max of $617 \mathrm{~nm}$. A stock solution of $60 \mathrm{ppm}$ was prepared. By the application of the dilution factors different ppm solution of the malachite green was prepared including 10, 20, 40ppm.Different concentration solutions of the adsorbate were utilized by changing the different parameters during the experiment.

\section{F. Adsorption experiments}

Adsorption experiments were performed under different parameters which included different amount of adsorbent from 5 to $50 \mathrm{mg}$, different time intervals ranging from $5 \mathrm{~min}$ to 60 min, and different $\mathrm{pH}$ from 2 to 13 . During adsorption experiments, $30 \mathrm{~mL}$ of $60 \mathrm{ppm}$ Malachite Green solution was taken in $50 \mathrm{~mL}$ flask, specific amount of adsorbent was added to it and then it was stirred at 600 RPM for some specified time. After that, the solution was centrifuged so that adsorbent get settled along with adsorbed dye. The remaining concentration of dye in the solution was checked on $3802 \mathrm{UV} / \mathrm{Visible}$ spectrophotometer at $617 \mathrm{~nm}$. From the remaining concentration, adsorbed concentration was calculated using Equation 1. The adsorption percentage was determined by using Equation 2. Further detail under different parameters is given below.

$$
\begin{aligned}
& \text { Adsorbed conc. }=\text { Initial conc. }- \text { remaining conc. } \\
& \text { Adsorption percentage }=\frac{\text { Adsorbed conc. }}{\text { Initial conc. }} X 100
\end{aligned}
$$




\section{Effect of contact time}

A $60 \mathrm{ppm}$ of the Malachite green solution was used and $30 \mathrm{mg}$ of the activated carbon was added to it. The solution was put on the stirrer for various time intervals at room temperature. Five samples were collected at various time interval including $5 \mathrm{~min}$, $10 \mathrm{~min}, 20 \mathrm{~min}$ and $60 \mathrm{~min}$. Each sample was analyzed by the application of the spectrophotometer so that to observe the contact time effect and sort out the dye percent removal.

\section{Effect of adsorbent Dosage}

For the observation of this parameter four $60 \mathrm{ppm}$ solution samples having $30 \mathrm{ml}$ of malachite green were prepared. Each of the solution has different quantity of the activated carbon including $5 \mathrm{mg}, 10 \mathrm{mg}, 30 \mathrm{mg}$ and $50 \mathrm{mg}$. Each sample was stirred for $60 \mathrm{~min}$ at $600 \mathrm{RPM}$ at room temperature. The absorbance of above mentioned each sample was determined. The obtained results were utilized to analyze the adsorbent dosage effect for the removal of the Malachite green dye.

\section{Effect of $p H$}

Four 60 ppm working solution of the Malachite green were prepared by maintaining each with various $\mathrm{pH}$ ranging from $2,5,7,13$ by the addition of the dilute Hydrochloric acid and dilute Sodium Hydroxide. $30 \mathrm{mg}$ of activated carbon was added to each of the solution of the $30 \mathrm{ml}$ and stirred each for two $\mathrm{h}$ at 600 RPM at room temperature. After the stirring each sample absorbance was sort out by UV-spectrophotometer hand then the percent absorbance was calculated.

\section{RESULTS AND DISCUSSIONS}

\section{A. Characterization}

FTIR spectra give useful information about the functional groups present in the material under observation. The IR spectrum of activated carbon is given in Fig. 1 (and Fig $1 \mathrm{~S}$ in supplementary data). The figure shows different peaks which corresponds to a particular functional group. The peak around $3450 \mathrm{~cm}^{-1}$ is due to the presence of alcoholic $\mathrm{OH}$ group in activated carbon; also it may be the peak of carboxylate $\mathrm{OH}$ group and water. The peak around $2100 \mathrm{~cm}^{-1}$ is due to presence of C-C triple bond in activated carbon. The peak around 1630 $\mathrm{cm}^{-1}$ may be attributed to $\mathrm{C}=\mathrm{C}$ stretching and $\mathrm{C}=\mathrm{O}$ stretching. The peak around $1400 \mathrm{~cm}^{-1}$ is due to the $\mathrm{C}-\mathrm{O}$ stretching of carboxylate group. The peak around $1086 \mathrm{~cm}^{-1}$ can be attributed C-O stretching [20]. The presence of these peaks shows the presence of different functionalities like alcohol, esters, carboxylic acid and alkyl functionalities in activated carbon. The presence $\mathrm{OH}$ group on the surface helps in adsorption of dye by hydrogen bonding. The presence of ester and carboxylic acid functionalities help in removing dyes by ionic interaction between the anionic portion of these groups and cationic portion of dye. Also these groups have hydrogen bonding interactions with Malachite Green. The triple bonded alkyl functionality helps in adsorption of Malachite Green through $\pi-\pi$ interaction.
The XRD pattern of activated carbon is shown in Fig. 2. The diffractogram does not exhibit a horizontal basic line. This shows that the major part of activated carbon is amorphous in nature. As amorphous material is found to have much more excellent adsorption properties than crystalline material, we can expect that the activated carbon will have excellent adsorption properties.

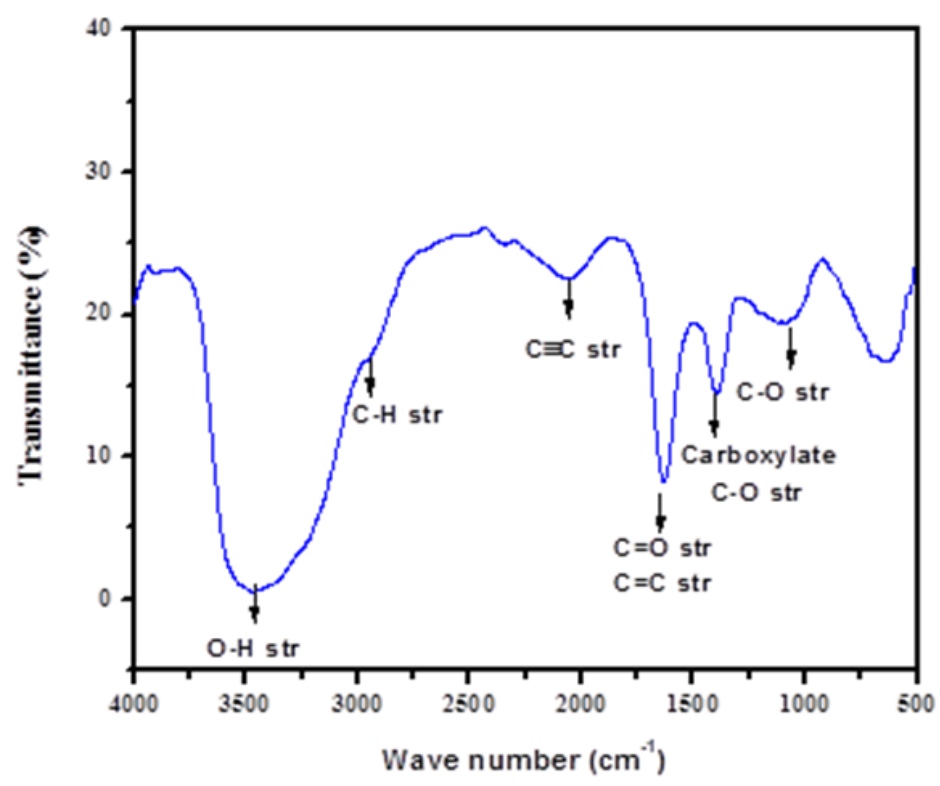

Fig. 1: FTIR spectrum of the prepared activated carbon.

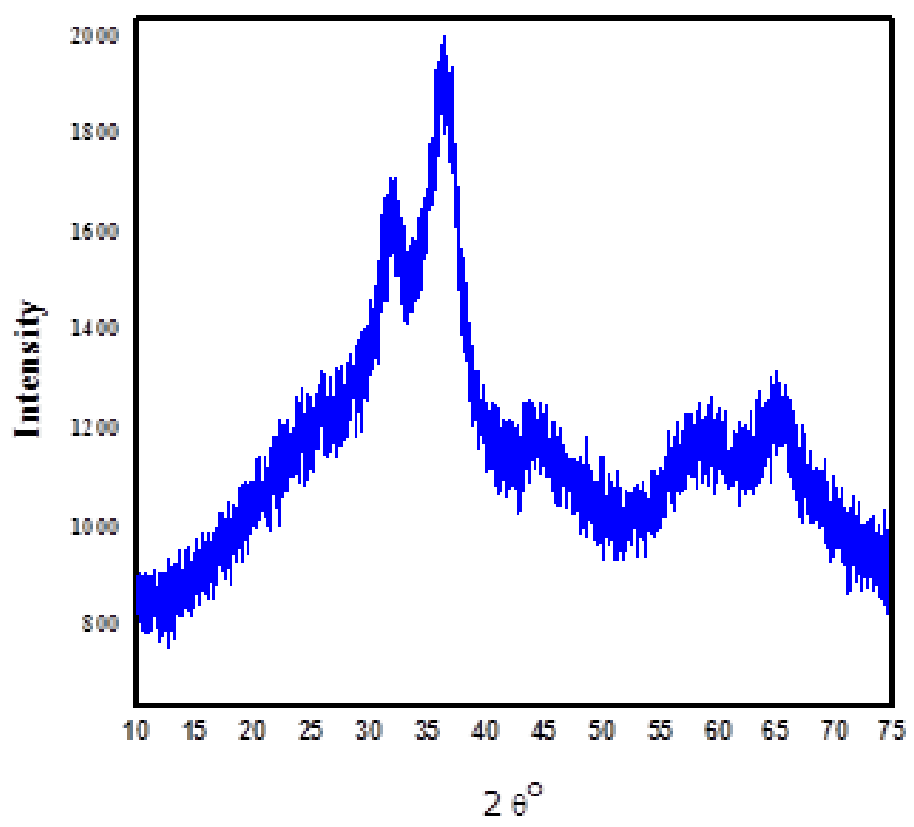

Fig. 2: XRD pattern of the prepared activated carbon. 


\section{B. Adsorption studies}

\section{A. 1. Standard curve formation}

The standard curve was obtained by preparing solutions of different concentrations ( 10 ppm, 20 ppm, 40 ppm and $60 \mathrm{ppm}$ ) from stalk solution and then, analyzing the solutions with $\mathrm{UV} / \mathrm{V}$ is spectrophotometer at $617 \mathrm{~nm}$ and finally drawing graph of absorbance v/s concentration. The standard curve is given in Fig 2S (in supplementary data).

The total adsorption, remaining concentration along with the percent adsorption were calculated by concerning the following given Equation 3 obtained from the standard calibration curve.

$$
\mathrm{y}=\text { Slope } \times \text { concentration }+ \text { Intercept }
$$

- $\quad$ where $y=$ absorbance

For the concentration the above equation is rearranged as follows

$$
\text { Concentration }=\frac{\mathrm{y} \text {-intercept }}{\text { Slope }}
$$

\section{a. Contact time's effect on adsorption}

There remains a great influence of the contact time during the adsorption process. From the Figure $\mathbf{3}$ and Table $\mathbf{1}$ we can conclude that initially the adsorption rate remains very much high however with the passage of the time a point is come where no any appreciable change in adsorption was observed. An equilibrium point was achieved after $20 \mathrm{~min}$ as from the figure we can judge that after $20 \mathrm{~min}$ any appreciable change in adsorption did not take place owing to availability of the lesser adsorbent's active sites. The high adsorption at initial time can be explained that initially the number of active sites remain very much high that make the adsorption to happen in ease and rapidly. However, because of the passage of the time duration the saturation takes place in the active sites of the adsorbent which leads the adsorption efficiency to be reduced.

Table 1: Adsorption of Malachite green by activated carbon at different contact time.

\begin{tabular}{cccccc}
\hline $\begin{array}{c}\text { Cont } \\
\text { act } \\
\text { time } \\
\text { in }\end{array}$ & $\begin{array}{c}\text { Absorba } \\
\text { nce } \\
\text { min }\end{array}$ & $\begin{array}{c}\text { Adsorbate } \\
\text { concentra } \\
\text { tion in } \\
\text { ppm }\end{array}$ & $\begin{array}{c}\text { Total } \\
\text { adsorpti } \\
\text { on in } \\
\text { ppm }\end{array}$ & $\begin{array}{c}\text { Remainin } \\
\text { g } \\
\text { concentra } \\
\text { tion in } \\
\text { ppm }\end{array}$ & $\begin{array}{c}\text { Percent } \\
\text { adsorpti } \\
\text { on }\end{array}$ \\
\hline 5 & 0.562 & 60 & 47.535 & 12.465 & 79.225 \\
10 & 0.210 & 60 & 55.029 & 4.971 & 91.715 \\
20 & 0.059 & 60 & 58.429 & 1.571 & 97.381 \\
60 & 0.049 & 60 & 58.646 & 1.354 & 97.743 \\
\hline
\end{tabular}

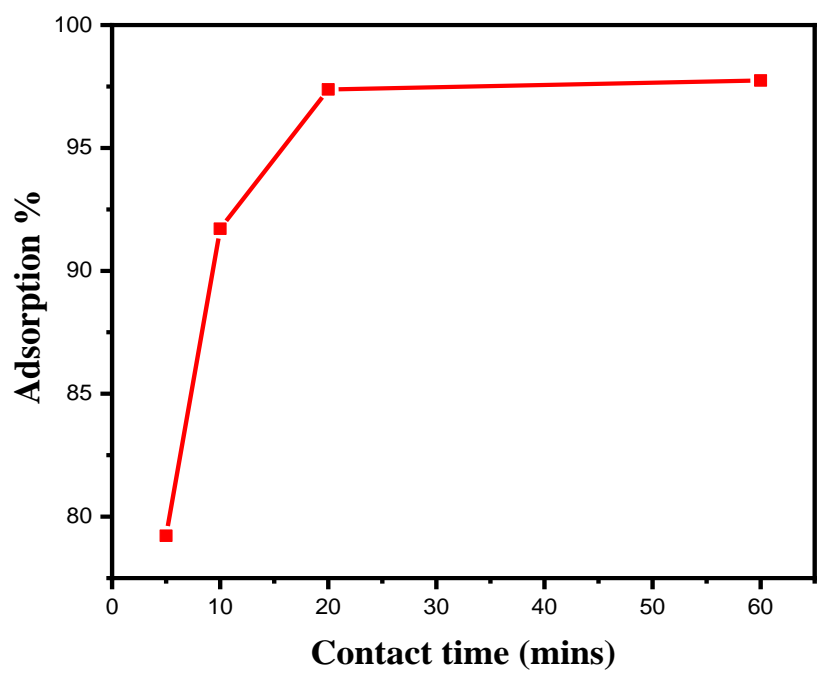

Fig. 3: Adsorption of Malachite Green by activated carbon at different contact time.

\section{b. Activated Carbon Dosage effect}

The activated carbon dose effect on the percent adsorption of the Malachite Green at the concentration of $60 \mathrm{ppm}$ was observed under the room temperature by taking the different dose of adsorbent including $5 \mathrm{mg}, 10 \mathrm{mg}, 30 \mathrm{mg}$ and $50 \mathrm{mg}$ in $30 \mathrm{ml}$ of the $60 \mathrm{ppm}$ solution. Figure 4 and Table 2 represents that by the increasing of the adsorbent dose the percent dye removal gets increased. The explanation of this is by the increasing of the adsorbent quantity the adsorption sites surface area gets increased hence high Malachite Dye removal take place. However, we can observe that an equilibrium point gets reached in which the further removal doesn't take place though the adsorbent dose is increased that might be because of particles themselves interaction with each other and result in coagulation [21].

Table 2: Adsorption of Malachite green by activated carbon using various Adsorbent amount.

\begin{tabular}{cccccc}
\hline $\begin{array}{c}\text { Adsorbe } \\
\text { nt } \\
\text { concentr } \\
\text { ation in }\end{array}$ & $\begin{array}{c}\text { Absorb } \\
\text { ance }\end{array}$ & $\begin{array}{c}\text { Adsorbat } \\
\text { e } \\
\text { concentr } \\
\text { ation in } \\
5\end{array}$ & $\begin{array}{c}\text { Total } \\
\text { adsorpt } \\
\text { ion in } \\
\text { ppm }\end{array}$ & $\begin{array}{c}\text { Remaini } \\
\text { ng } \\
\text { concentr } \\
\text { ation in }\end{array}$ & $\begin{array}{c}\text { Percen } \\
\mathrm{t} \\
\text { adsorpt } \\
\text { ion }\end{array}$ \\
10 & 1.304 & 60 & 31.465 & 28.538 & 52.441 \\
30 & 0.075 & 60 & 58.084 & 1.916 & 96.806 \\
50 & 0.052 & 60 & 58.582 & 1.418 & 97.636 \\
\end{tabular}




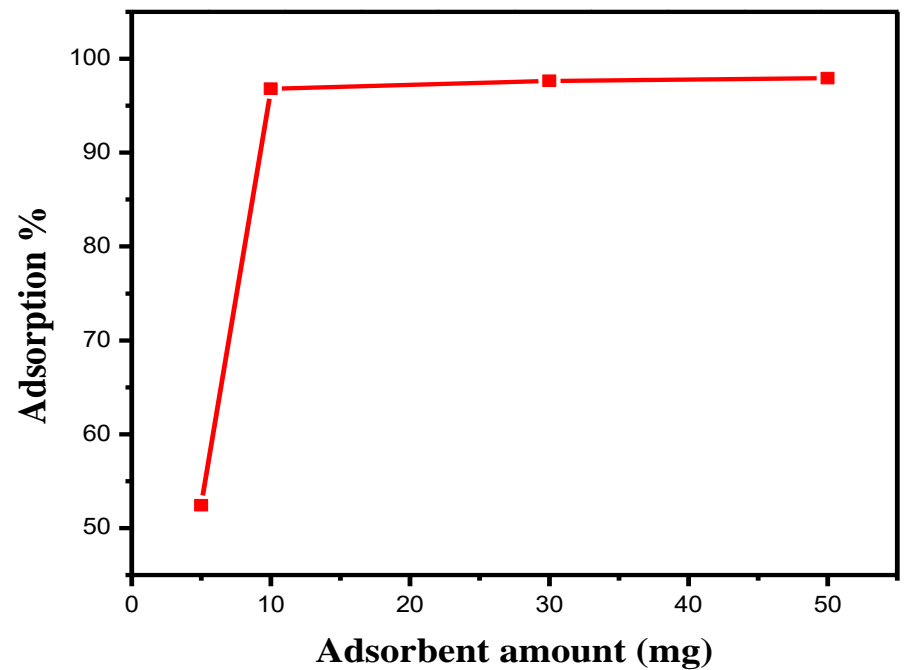

Fig. 4: Adsorption of Malachite green by activated carbon using various Adsorbent amount.

\section{Initial pH effect}

The dye solution's initial $\mathrm{pH}$ plays an important role in the adsorption process because of the great impact of $\mathrm{pH}$ on the surface characteristics of the adsorbent along with the dye's molecule ionization [22]. The Figure 5 and Table 3 represents initial $\mathrm{pH}$ effect on the adsorbed dye amount by the Date fiber based activated carbon. In this experiment work the $60 \mathrm{ppm}$ solution in a $30 \mathrm{ml}$ of the dye solution was under studied at $\mathrm{pH}$ range of 2, 5, 7 and 13. The mentioned $\mathrm{pH}$ was obtained utilizing the $0.1 \mathrm{M}$ solution of $\mathrm{HCl}$ and $\mathrm{NaOH}$ by the help $0 \mathrm{f}$ a $\mathrm{pH}$ meter. From the figure 5 we can conclude that the optimum adsorption was shown at the $\mathrm{pH}$ range of 5 to 7 while at $\mathrm{pH} 13$ the adsorption of dyes reduces greatly. At high acidic $\mathrm{pH}$ of 2 very little adsorptions was shown. The explanation of this can be that in high acidic $\mathrm{pH}$ there remains a competition between the protons and Malachite Green's ion for the adsorption sites of Activated Carbon; hence this leads to the inhibition of adsorption of the dyes. On the other hand, at higher $\mathrm{pH}$ greater than 7 the given dyes ions in aqueous solution interact with the presence $\mathrm{OH}$ groups that leads to the formation of white precipitate hence the color of the dye gets discharged resultantly reduction in adsorption is observed accordingly with literature [22].

Table 3: Adsorption of Malachite green by activated carbon at different $\mathrm{pH}$.

\begin{tabular}{cccccc}
\hline $\mathrm{pH}$ & Absorbance & $\begin{array}{c}\text { Adsorbate } \\
\text { concentration } \\
\text { in ppm }\end{array}$ & $\begin{array}{c}\text { Total } \\
\text { adsorption } \\
\text { in ppm }\end{array}$ & $\begin{array}{c}\text { Remaining } \\
\text { concentration } \\
\text { in ppm }\end{array}$ & $\begin{array}{c}\text { Percent } \\
\text { adsorption }\end{array}$ \\
\hline 2 & 0.843 & 60 & 41.448 & 18.552 & 69.08 \\
5 & 0.371 & 60 & 51.671 & 8.329 & 86.118 \\
7 & 0.132 & 60 & 56.848 & 3.152 & 94.746 \\
13 & 1.324 & 60 & 31.029 & 28.9701 & 51.715 \\
\hline
\end{tabular}

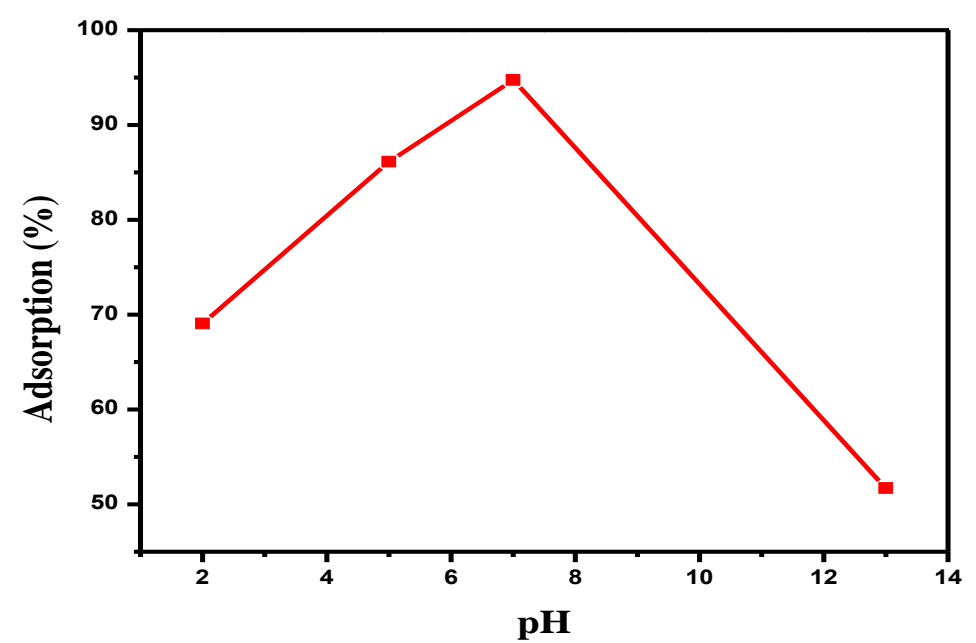

Fig. 5: Adsorption of Malachite green by activated carbon at various $\mathrm{pH}$.

\section{CONCLUSIONS}

Low cast adsorbent, activated carbon was prepared from date trunk fiber, by using chemical activation using $\mathrm{H}_{3} \mathrm{PO}_{4}$ as activating agent. The prepared activated carbon was checked by FTIR spectroscopy to find those functional groups on the surface of activated carbon which are very important for adsorption. In order to find out the crystallinity, XRD result was checked. It was found to have amorphous nature which is very suitable for adsorption. Finally the prepared activated carbon was subjected for adsorption of Malachite green adsorption from water. The optimum conditions determined were adsorbent dosage $0.5 \mathrm{~g}$, contact time $20 \mathrm{~min}$ and $\mathrm{pH} 5-7$.

We can conclude that activated carbon prepared from the date palm trunk fiber can be utilized as an abundant and low cost and an efficient adsorbent for the treatment of the waste water containing the Malachite Green or other dye effluent.

\section{REFERENCES}

[1] S. Wong et al., "Adsorption of anionic dyes on spent tea leaves modified with polyethyleneimine (PEI-STL)," J. Clean. Prod., 2019.

[2] T. R. Das, S. Patra, R. Madhuri, and P. K. Sharma, "Bismuth oxide decorated graphene oxide nanocomposites synthesized via sonochemical assisted hydrothermal method for adsorption of cationic organic dyes," J. Colloid Interface Sci., 2018.

[3] K. Hunger, "Industrial dyes: chemistry, properties, applications," J. Ameri. Chem. Soci. 2007.

[4] M. a Mohammed, a Shitu, and a Ibrahim, "Removal of Methylene Blue Using Low Cost Adsorbent : A Review," Res. J. Chem. Sci., 2014.

[5] M. Sulyman, J. Namieśnik, and A. Gierak, "Adsorptive Removal of Aqueous Phase Crystal Violet Dye by Low-Cost Activated Carbon Obtained from Date Palm (L.) Dead Leaflets," Eng. Prot. Environ., 2016.

[6] A. M. Kocabas, H. Yukseler, F. B. Dilek, and U. Yetis, “Adoption of European Union's IPPC Directive to a textile 
mill: Analysis of water and energy consumption," J. Environ. Manage., 2009.

[7] E. John, "Industrial Reuse and Recycle of Wastewaters Literature Review."

[8] A. G. R Ananthashankar, "Production, Characterization and Treatment of Textile Effluents: A Critical Review," J. Chem. Eng. Process Technol., 2013.

[9] M. A. M. Salleh, D. K. Mahmoud, W. A. W. A. Karim, and A. Idris, "Cationic and anionic dye adsorption by agricultural solid wastes: A comprehensive review," Desalination, vol. 280, no. 1-3. pp. 1-13, 2011.

[10] D. R. Lima, L. Klein, and G. L. Dotto, "Application of ultrasound modified corn straw as adsorbent for malachite green removal from synthetic and real effluents," Environ. Sci. Pollut. Res., 2017.

[11] M. A. Hassaan and A. El Nemr, "Health and Environmental Impacts of Dyes: Mini Review," Am. J. Environ. Sci. Eng., 2017.

[12] M. S. Islam and M. Tanaka, "Impacts of pollution on coastal and marine ecosystems including coastal and marine fisheries and approach for management: A review and synthesis," Marine Pollution Bulletin. 2004.

[13] B. Padhi, "Pollution due to synthetic dyes toxicity \& carcinogenicity studies and remediation," Int. J. Environ. Sci., 2012.

[14] V. K. Gupta, I. Ali, T. A. Saleh, A. Nayak, and S. Agarwal, "Chemical treatment technologies for waste-water recycling An overview," RSC Advances. 2012.

[15] C. Zheng, L. Zhao, X. Zhou, Z. Fu, and A. Li, "Treatment Technologies for Organic Wastewater," in Water Treatment, 2013.

[16] V. Vadivelan and K. Vasanth Kumar, "Equilibrium, kinetics, mechanism, and process design for the sorption of methylene blue onto rice husk," J. Colloid Interface Sci., 2005. [17] E. Studies, "Charles University in Prague Faculty of Science Institute for Environmental Studies," 2014.

[18] S. Medidi et al., "Visible Light Photocatalytic Degradation of Methylene Blue and Malachite Green Dyes with CuWO4GO Nano Composite," Mod. Res. Catal., 2018.

[19] C. Srinivasakannan and Z. M. Abu Bakar, "Production of activated carbon from rubber wood sawdust," Biomass and Bioenergy, 2004.

[20] W. Nakbanpote, P. Thiravetyan, and C. Kalambaheti, "Comparison of gold adsorption by Chlorella vulgaris, rice husk and activated carbon," Miner. Eng., 2002.

[21] M. S. Zafar, M. Tausif, M. Mohsin, S. W. Ahmad, and M. Zia-Ul-Haq, "Potato Starch as a Coagulant for Dye Removal from Textile Wastewater," Water. Air. Soil Pollut., 2015.

[22] M. Haroon et al., "Synthesis of carboxymethyl starch-gpolyvinylpyrolidones and their properties for the adsorption of Rhodamine 6G and ammonia," Carbohydr. Polym., 2018.

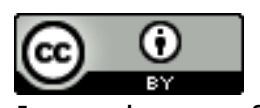

Journal of Applied and Emerging Sciences by BUITEMS is licensed under a Creative Commons Attribution 4.0 International License. 